\title{
Effective business models for electric vehicles
}

\author{
Ileana GAVRILESCU \\ The Bucharest University of Economic Studies, Bucharest, Romania \\ gavrilescu_ileana@yahoo.com
}

\begin{abstract}
The proposed study aims to use asyncretic and synthetic approach of two elements that have an intrinsic efficiency value: business models and electric vehicles. Our approach seeks to circumscribe more widespread concerns globally - on the one hand, to oil shortages and climate change - and on the other hand, economic efficiency to business models customized to new types of mobility. New "electric" cars projects besiege the traditional position of the conventional car. In the current economy context the concept of efficiency of business models is quite different from what it meant in a traditional sense, particularly because of new technological fields. The arguments put forward by us will be both factual and emotional. Therefore, we rely on interviews and questionnaires designed to fit significantly to the point of the study. Research in the field of new propulsion systems for vehicles has been exploring various possibilities lately, such as: electricity, hydrogen, compressed air, biogas, etc. Theoretically or in principle, it is possible for tomorrow's vehicles to be driven by the widest variety if resources. A primary goal of our study would be to theoretically reconsider some of the contemporary entrepreneurship coordinates and secondly to provide minimum guidance for decision-making of businesses that will operate in the field of electric mobility. To achieve this, we shall specifically analyze an electric mobility system but in parallel we will address business models that lend themselves effectively on aspects of this field. With a methodology based on questionnaires that had to overcome the conventional mechanism using some of the most unusual ingredients, we hope that the results of our research will successfully constitute a contribution to the goals and especially as a means of managerial orientation for entrepreneurs in the Romanian market.
\end{abstract}

Keywords: business model, economic efficiency, electric mobility, environment, entrepreneurship.

List of acronyms/Abbreviations:(EVs) = Electric vehicles; $($ EMS $)=$ Electric Mobility System; $(\mathrm{BM})=$ Business models; $($ ERO) $=$ Electric Recharge Operator.

\section{Introduction}

The golden age of cars running on combustion engines seems to be approaching its final stage, both due to a depletion of resources and due to the harmful effects pollution has on the environment and on people's health. Research in the field of new propulsion systems for vehicles has been exploring various possibilities lately, such as: electricity, hydrogen, compressed air, biogas, etc. Theoretically or in principle, it is possible for tomorrow's vehicles to be driven by the widest variety if resources. Practically, however, history teaches us that it is very likely for one of these resources to become predominant. Today's world is changing at an unprecedented pace and it is very difficult for anyone to foresee an exact model, even on a medium term.

James H. Kunstler, the author of a very popular book released in the Unites States in 2005 - "The Long Emergency: Surviving the Converging Catastrophes of the Twenty- 
first Century" even talks about possible social turmoil that might be triggered by the depletion of fossil fuels and the transition to other energy sources:

"A more likely scenario is the one where new fuels and technologies will never be able to fully replace fossil fuels at the scale, rate and in the manner they are being consumed in the world right now. What's usually not fully understood about this situation is that the developed world will start suffering long before the oil and gas run out."

PICBE| 37

There is no doubt about the fact that such a dark scenario might indeed happen, but that would require a relatively sudden depletion of fossil resources, at global scale. And this is precisely the probability that strikes us as unrealistic. While, a gradual evolution of this process should not be regarded with fatalism, even if it does require a constant "belt-tightening".

By 2016, the most remarkable research area in terms of its tendency to develop new propulsion systems has been the electricity area. The development trend in the field of vehicles' electric mobility has thus been advances by Kley (2011): "The first electric vehicles are being released on the marker right now, as a consequence of technological improvements and their market penetration is expected to become larger and larger over time.

But, so far, this release of electric cars on the market has often been done with stumbles and improvisations, generated by an obvious cause: the lack of new, upgraded and updated business models, that would amount to a sustainable ideological support. "Consequently, the individual interested parties are uncertain of which business models would be indeed more efficient in this redirecting process, in terms of profits" (Kley et al., 2011).

Traditional business models were strategic management practice systems, mainly focused on sales and product oriented, through which entrepreneurs were pursuing their value surplus projecting and producing the goods and services more or less using they're flair, respectively more or less conscious of the final product's life cycle - under the aspects of quality, usefulness and its performance, more or less concerned about customer satisfaction.

\section{The need for new business models in the field of electric vehicles, reflected in the literature}

The issue analysed by us here, has been very well covered by the specialised literature. After having read several dozens of titles, we came to the conclusion that, authors' attitudes could be split into two models: one optimistic and the other one pessimistic. Hence, on one hand, we have numerous enthusiasts of the idea of progress through electric motorisation while, on the other hand, we have a lot of critics, who are sceptical about humanity's chances of completing the above mentioned transition, successfully.

James H. Kunstler is a pessimist, at least in his book mentioned above. We are quoting a fragment of his work here, which, given its c size, is intended to represent a synthesis of several authors' views: "The attraction of cheap gas has been so seducing and it has induced such a hypnotic contentment, that we've stopped paying attention to the essential nature of these miraculous gifts received from earth: the fact that they are there 
in limited reserves, unevenly spread across the globe... Nowadays, even people from our own culture, who should know better, are strongly wishing to see, in a few years, a smooth, trouble-free transition from fossil fuels to their alleged replacements: hydrogen, solar power, or something else... In fact, in the best case scenario, some of these technologies might need dozens of years to fully develop - which means that we should expect a very turbulent transition period, between the moment of oil depletion and whatever comes afterwards." Although he describes himself as "objective" and he even promotes, in his book, the idea that Humanity has a very high ability to adapt to new realities, in our opinion, Kunstler allows himself to be overwhelmed by the psychosis of today's world demographic over-crowding and, consequently, by the fear that the existing governing bodies would not be able to manage a major crisis.

Coming back to our research direction, there are plenty of signs indicating that, the classic business models used in the field of combustion engine vehicles, cannot be transferred to the electric mobility concept, mainly because of the great technological differences exiting between the two fields.

The efficiency of electric mobility systems may not depend as much on the invention of electric vehicles (Evs), but rather on the efficiency of the business models (BM) used - for all the system components.

The natural question arising in this situation is whether the existing traditional business models may still be compatible with the new technological models. The business world cannot easily forget the relatively recent examples provided by the lamentable collapses of Kodak and Encyclopaedia Britannica, who lacked the capacity to anticipate the digital revolution and thus, they failed to adopt a change of their business models that would have saved the companies (Klein, 2013).

One may expect the development of EMS (Electric Mobility System) to trigger the appearance of new, innovative entrepreneurs, on the transport market, entrepreneurs with new management ideas, that would inevitably impose new ways to create value, and, respectively, new business models. However, the Electric Mobility System (EMS) is very complex, comprising both the research in this area, the electricity producing industry, the battery producers, the vehicle producers, various part and component suppliers (both constructive and electronic), as well as countless other service suppliers (trade, maintenance, repairs, recycling, infrastructure, etc. ) For instance, a new business model meant to speed up the introduction of electric cars on the market, would require an Electric Recharge Operator (ERO) to develop a smart battery recharge network. All these factors would have to be taken into account when assessing the efficiency of an electric mobility based business and all these factors must be appropriately analysed, using the most compatible specific mechanisms.

"New technologies might extend the role held by organisations in improving management decisions and in accelerating the development of new products and services", Bughin once foresaw (Bughin et al., 2010). However, as long as the implementation of new EMS development actions is threatened by inefficiency, it is normal for the new shifts to make up an economic and sociological issue. 
Some authors who are more confident- such as Lovins et al., (2007), think that: "Some very simple changes brought to the way we conduct our own businesses, based on advanced technologies meant to render more resources productive, may bring amazing benefits both for the current shareholders and for the next generations".

Fabian Kley, Christian Lerch, David Dallinger (2010) have even noticed the following reality: "In this industry, suppliers have been using the principle of new business models for their clients, for a while now" and they also note, quoting Matzen et al. (2005), that: "These new business models have been trying to use additional services to design the product in such way to increase the benefits for the client and to provide the supplier with a competitive advantage". By extrapolating, the above mentioned authors concluded that: "This basic idea could also be transferred to innovative business models related to electric mobility."

In order to highlight the concrete transition to new business models, we invoke the mutation in the buyer-user status -from the status of "consumer" into that of"prosumer". If the managers do not understand the contents of this change and ignore the obvious reality that they no longer have absolute control over their products, the traditional business model can change "under their noses" in the very immediate future and can lead to loss of profitability and, probably, bankruptcy

Another resolution published in the work entitled: "Can innovative business models overcome resistance to electric vehicles? Better Place and battery electric cars in Denmark.", written by Thomas Budde Christensen, Peter Wells, Liana Cipcigan, (2012), is also relevant from the perspective of this new field of "electric mobility based on efficient business models": "At theoretical level, one can conclude that, in order to understand the broader role held by these models in achieving a company's objectives and to understand the existing structural obstacles related to organisation and technical innovation, the theorisation of these business models needs a perspective that goes beyond the typical principle of "creating and capturing value"."

Finally, regardless of the nature of the business model experimentally adopted by an entrepreneur, one must retain the idea captured in Alexander Osterwalder's, Yves Pigneur's, Christopher L. Tucci's work (2005) named: “Clarifying Business Models: Origins, Present and Future of the concept", e.g.: “... a strong business model may be badly managed just as a weak business model may be successful thanks to some strong management and application skills."

This last idea is particularly evoking the entrepreneurs' and the managers' responsibility to assume the foreseen change of vision, under the condition of their business's continuous performance.

The issue described here is obviously general or universal in nature, due to its global dimension. However, we aim to take a more realistic action, e.g.: to research the Romanian dimension of this issue, in such way to discover its potential particularities, that would later be integrated in a popper- style flexible paradigm (Popper, 1934). More specifically, we are particularly interested in how prepared the Romanian mentality is 
right now, for the inevitable transition towards this new "electric" technology and towards the new business models that will soon become typical for this transition.

\section{Methodology}

In order to analyse, from a syncretic and synthetic viewpoint, the efficiency of business models and the technical efficiency of electric vehicles, for the purpose of reconsidering, later, some of the entrepreneurial coordinates that are typical for our time - thus also providing minimum guidelines for any future decisions in the field of electric mobility , we deemed as necessary, the use of a method based on opinion polls - thus employing questionnaires and interviews.

The opinion poll proposed by us, has materialised as a self-administered questionnaire, with 15 questions - where the first 5 questions were identification questions. First, we broke down the issue at hand, into several dimensions and then, we broke down each dimension into indicators. The indicators thus determined, were turned into questions in the questionnaire. When the questions were phrased, we were equally focused on phrasing the answer options as well as the items. In terms of typology, the questions were both factual and opinion-focused; both open, closed and mixed. Out of the 10 content questions, only one was meant as a filter question.

Relative to shaping an appropriate business model for the Romanian market, raised issues concerning the propensity of respondents to the idea of monitoring the development of the operations of the product by the manufacturer and dealer on as much of the product life as possible, in order that the manufacturer can systematically consult the opinions of the buyer-user related to quality and to the idea that a service provider can provide alternative long-term hiring of vehicles.

The questionnaire was sized for a representative sample, determined by the constraints generated by the fact that all respondents had to be automobile users and they had to have at least 5 years of experience in using a car systematically. Thus, we took the opinions of people who were well informed and held a significant experience in automobile usage. Our respondent's pertinence was supposed to provide us, in principle, with a higher level of accuracy in terms of our results. Later, when we proceeded to actually serve the questionnaire to our subjects, we realised that we should have provided for another condition as well.

In order to break down the issue and to define certain indicators-questions, we split our respondents by age groups, for the purpose of delimiting them by their driving experience - according to the criterion advanced by the National Institute of Statistics in Romania: under 20; 20 to 30 years old; over 30 years old. The questionnaire was filled in by 151 subjects, coming from a wide variety of socio-professional backgrounds and from a sufficient variety of regional areas - to make the sample as representative as possible. By consulting various demographic documents, we also tried to obtain an adequate, proportional representativeness. The subjects were not asked to provide their names, addresses or other identity data and thus, the issue of confidentiality has not arisen in any way. The time provided to fill in the questionnaire was two days. 
Accidentally, the first survey technique used was "face to face" interviewing. This left us unravelled for a while because the two people approached, did not seem to be informed enough to provide us with answers that would consistently contribute to our final conclusions.

That's why, we decided to distribute, along with our questionnaire, a short printed documentation material (5 pages) - presented as a breaking news in this field, and we kindly asked our subjects to take the time and also consult other media channels, during the two days they had to fill in the questionnaire. The action was conducting according to this latter plan. In the first day, between 8:00 and 11:15 in the morning, the four members of our survey team managed to distribute 163 copies of the materials although our proposed studio sample was only supposed to include 151 respondents. Besides, in order to make sure that our respondents were serious, on the evening of that first day, each of the four members of our team, called a quarter of the people who had received the materials, to remind them to make time for providing us with the benevolent help they had promised to give us. On the second evening, the persons who seemed to be "distracted" on the previous day were called again, under the pretext of setting up a time and a place for the meeting that was scheduled to take place on the third day. Our anticipation proved to be right. Due to "unforeseen events" 11 of the people who had received our materials, could not meet us on the third day. Out of the 152 filled in questionnaires, we decided to "forget" one - the one that did not provide coherent answers due to the fact that it had been filled in in a hurry.

We used the "face to face" techniques with 19 of the respondents, with 17 others we solved the problem by e-mail, 5 talked to us by phone while the rest - 110 , came to our meeting with the questionnaires already filled in. Once we had all the questionnaires back, we started analysing the data. The first operation was to code the respondents and their answers. Based on some qualitative data we were also able to make a qualitative analysis.

Counted in percentages, the data obtained from our questionnaires was represented graphically, for a better understanding of the attitudes shown and for a clearer identification of our conclusions.

\section{Results}

Due to the homogeneity of the answers received, there was no need for an additional criterion, e.g., for a new coding of the subjects based on the interviewing technique used.

The most spectacular attitude shown by our respondents was related to the "need to complete the transition to electrical motorisation within maximum 10 years." Younger people, under the age of 20, proved to be more radical in this issue than older people $-74 \%$ for the under 20 group, compared to $46 \%$ for the 30 to 40 and $30 \%$ for those over the age of 30 . Besides the impetuosity specific to young age, this may also prove that younger people were better informed on this issue and they were more realistically worried about environmental quality in the near future. 


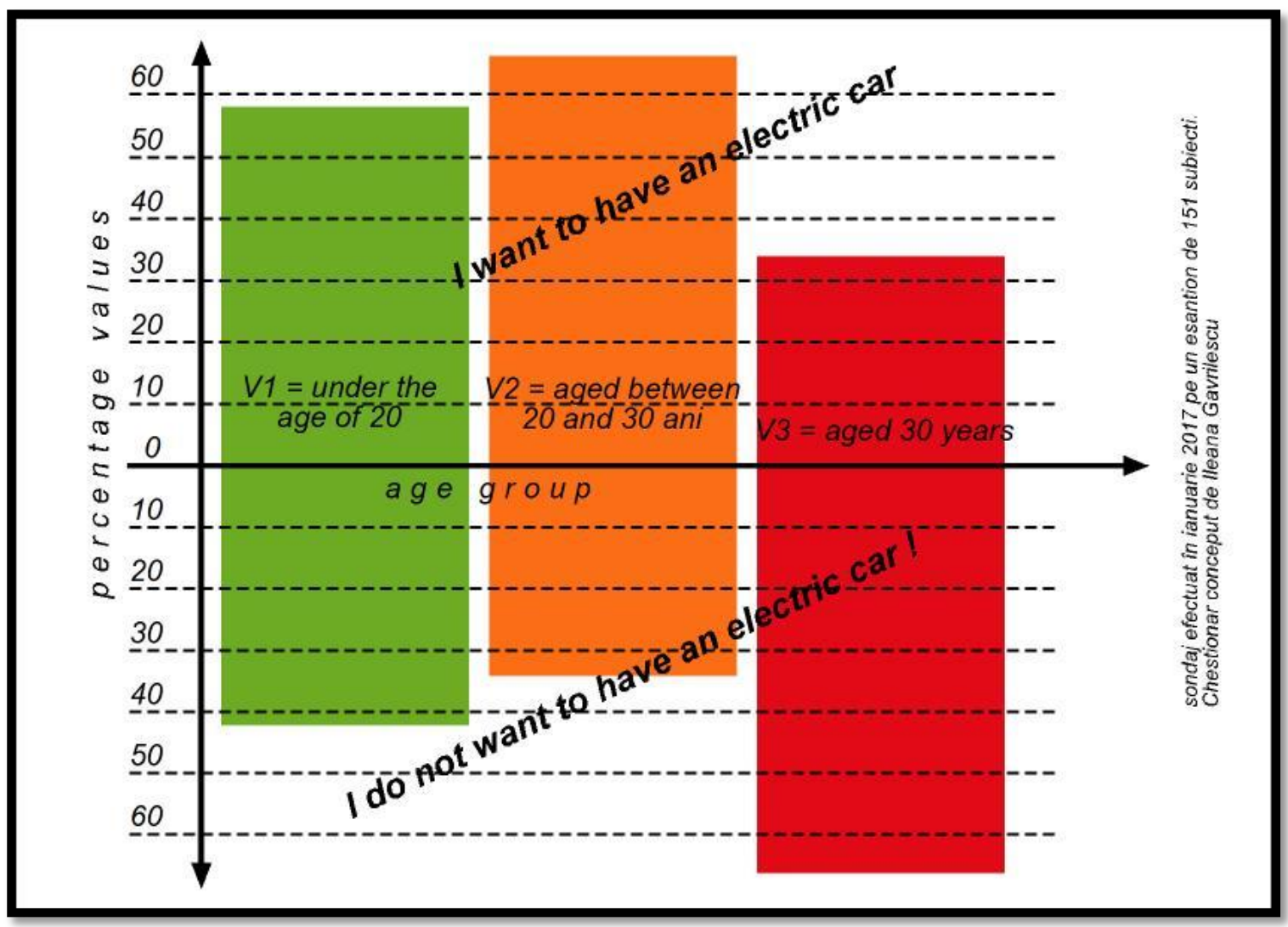

PICBE 42

Figure 1. Percentages of people who wish to acquire an electric car, by age groups

Source: Authors' own research results/contribution.

The proportional research that we conducted here has the merit of highlighting at least three very important aspects of the Romanian society, in relation to the issue at hand:

- Everybody is unanimously preoccupied with the environmental quality (81\% for youngsters under the age of 20; 54\% for people between the age of 30 and 40; 62\% for people over the age of 30).

- Most people have an obvious intention to buy an electric vehicle, within maximum 5 years (58\% for youngsters under the age of 20; 65\% for people between the age of 30 and 40; 33\% for people over the age of 30); and

- The State must get involved in this process one way or the other, by providing budget subsidies (regardless of who's getting such sponsorship - the vehicle producer, the buyer, upon purchasing the vehicle, the specific infrastructure developer (charging stations, etc.) or the user, for the charging cost): 66\% for youngsters under the age of 20; 57\% for people between 30 and 40; 42\% for people over the age of 30 ).

Other item-questions that revealed different proportions of fears related to the autonomy of electric cars, to their dynamic performances and the easiness to recharge the batteries, depending on the various age groups, have not revealed much different results from the ones recorded in other surveys conducted in the Netherlands, France and the USA. 


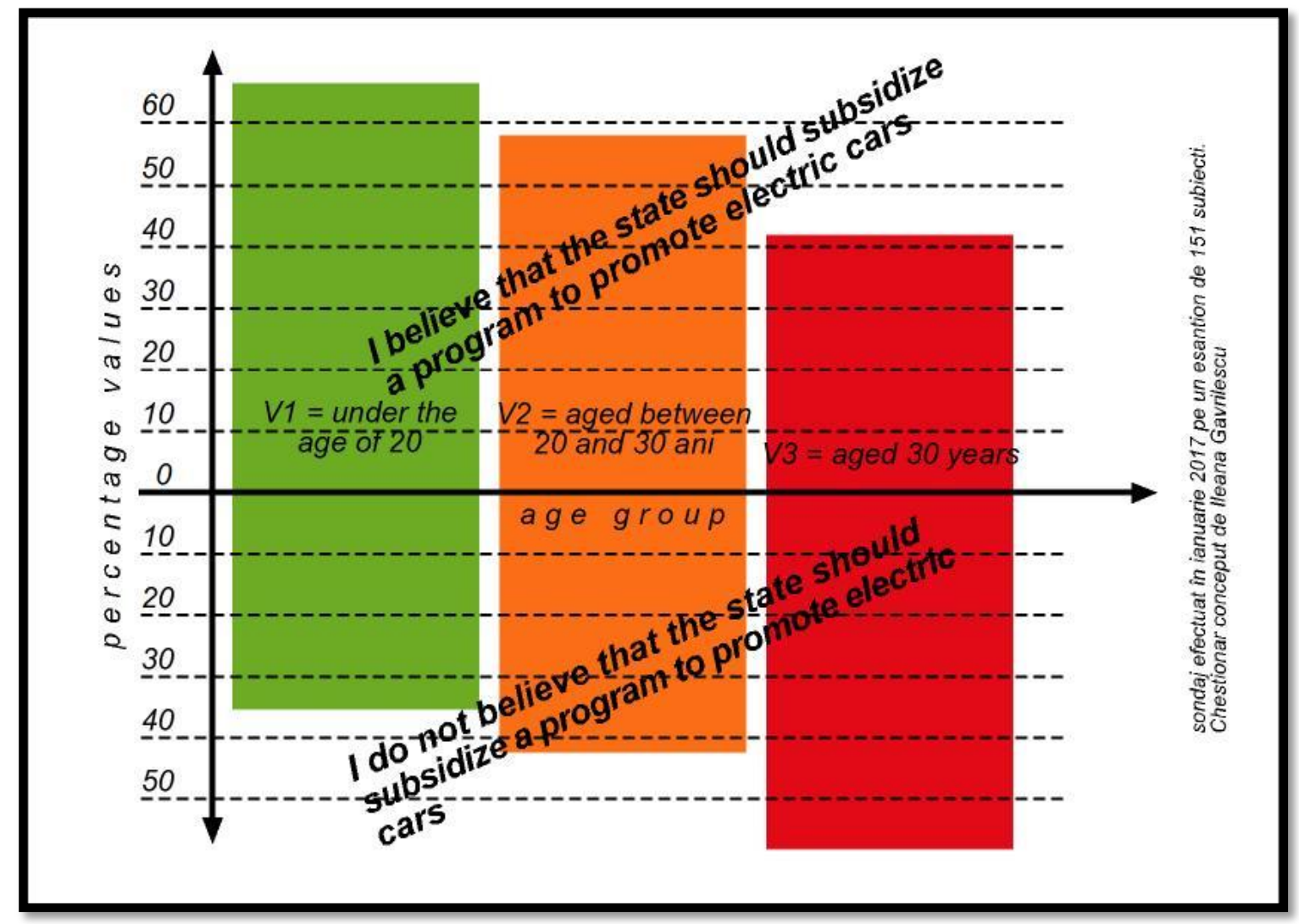

PICBE 43

Figure 2. Percentages of people wanting a subsidy programme for the development of electric mobility, by age groups

\section{Conclusions}

Source: Authors' own research results/contribution.

No matter how high the error margins generated by approximations and by random distinguishing may be, the percentage differences obtained, outline the psychological profile of the Romanian consumer.

Some aspects of this poll may have practical relevance for the entrepreneurs and managers who think of starting or adapting an electric mobility business, on the Romanian market, for banking economists, for decision-makers in the energy industry and for numerous other suppliers and entrepreneurs eyeing the adjacent domains of this new industry.

Also, this poll could be used as recorded or archived data (especially numeric values) to be employed for future comparatives studies. Objectively speaking, at this point in time, this survey's fundamental contribution to the overall theme is very modest, so we are encouraged by the hope that, our collected data and our interpretations could be further valorised in the future, in the above mentioned studies.

However, in our opinion, the most interest aspect of this survey was the issue revealed by the application of this questionnaire, related to the poor(er) level of information held by our subjects on this topic. We have discovered that, besides setting up the appropriate problems for the topic at hand, and the indicators leading to the item questions, one can also be confronted with circumstance-related problems, that need to 
be solved quickly, in an efficient and inspired manner. It is precisely in relation to these types of problems, that researchers have to prove their perspicacity, which is so badly needed for their intelligent and intellectual statute.

\section{References}

Kunstler, J.H. (2005). Îndelungata criză. Cum să supraviețuim catastrofelor convergente ale secolului XXI, Atlantic Monthly Press.

Kley, F. (2011). Neue Geschäftsmodelle zur Ladeinfrastruktur, Working Paper Sustainability and Innovation No. S 5/2011, Fraunhofer ISI, Karlsruhe.

Klein, K., (2013). Seeing What Others Don't: The Remarkable Ways We Gain Insights, traducere Dan Crăciun, București, Ed. Publica 215.

Bughin, J., Chui, M., Manyika, J. (2010). Clouds, big data, and smart assets: Ten techenabled business trends to watch, McKinsey Quarterly 56(1), 75-86.

Lovins, A., Lovins, H., and Hawken, P. (2007). A road map for natural capitalism, https://hbr.org/2007/07/a-road-map-for-natural-capitalism, (accessed on 13 November 2016).

Lerch, C., Kley, F., Dallinger, D. (2011). New business models for electric Cars - A holistic approach, Energy policy, 39(6), 3392-3403.

Matzen, D.; Tan, A.R.; Andreasen, M. (2005). Product/Service-Systems: Proposal for Model and Terminology. In: 16. Symposium "Design for X", Neukirchen, 13-14 October 2004, http://www.ep.liu.se/ecp/077/044/ecp10077044.pdf, (accessed on 28 February 2017).

Afuah, A., (2003). Business models: a strategic management approach, Boston; London: McGraw-Hill/Irwin, 2003.

Christensen, T.B., Wells, P., Cipcigan, L. (2012). Can innovative business models overcome resistance to electric vehicles? Better Place and battery electric cars in Denmark, Energy Policy, 48 (2012), 498-505.

Osterwalder, A., Pigneur, Y., Tucci, C. L. (2005). Clarifying business models: origins, present and future of the concept, https://pdfs.semanticscholar.org/01bb/3767f63880825ffa873c2e985f5df40780 5a.pdf, (accessed on 08 July 2016).

Burke, T.E. (1983). The Philosophy of Popper, Manchester: Manchester University Press.

Gómez, T., Román, S., Momber, I., Abbad, M.R.,Miralles, A.S. (2011). Regulatory framework and business models for charging plug-in electric vehicles: Infrastructure, agents, and commercial relationships, Energy policy, 39(10), 6360-6375.

Matulka, R. (2014). The History of the Electric Car available at http://energy.gov/articles/history-electric-car, (accessed on 12 November 2016).

Lund, H., Kempton, W. (2008). Integration of renewable energy into the transport and electricity sectors through V2G, Energy Policy, 36 (9), 3578-3587.

Popper, K., (1934). Logica cercetării”, Editura Științifică, București, 1981. 